\title{
Notas sobre a voluntariedade das ações a partir de Wittgenstein
}

Notes on the voluntariness of actions based on Wittgenstein

\author{
Mirian Donat ${ }^{*}$
}

Universidade Estadual de Londrina, Londrina, PR, Brasil

\section{Resumo}

O artigo tece algumas considerações acerca da voluntariedade das ações a partir de observações da filosofia tardia de Wittgenstein. Estas considerações passarão por três momentos: primeiro apresentamos a crítica de Wittgenstein aos modelos causais de explicação da ação voluntária, contra os quais defende uma análise gramatical dos termos ligados à vontade, demonstrando os diferentes lugares que estes ocupam nos jogos de linguagem; depois mostramos que, a partir da compreensão da voluntariedade enquanto expressão de regras gramaticais, pode-se compreender que a voluntariedade "caracteriza" as ações, aproximando esta discussão com a discussão acerca da visão de aspetos e, por fim, mostramos o papel e o lugar do sujeito e da perspectiva de primeira pessoa para a correta compreensão da ação voluntária.

Palavras-chave: Ação voluntária. Vontade. Aspectos. 


\section{Abstract}

The article makes some considerations about the action's voluntariness based on observations of the Wittgenstein's late philosophy. These considerations will be demonstrated in three moments: first we present Wittgenstein's critique of the causal models of explanation of voluntary action, against which he defends a grammatical analysis of terms linked to the will, demonstrating the different places they occupy in language games; then we show that, from the understanding of voluntariness as an expression of grammatical rules, one can understand that voluntariness "characterizes" actions, bringing this discussion closer to the discussion about the view of aspects and, finally, showing the role and the place of the subject and the first-person perspective for the correct understanding of voluntary action.

Keywords: Voluntary action. Will. Aspects.

\section{Introdução}

No parágrafo 621 das Investigações filosóficas, Wittgenstein coloca a seguinte questão: "Se 'ergo o meu braço', o meu braço ergue-se. E o problema surge: o que é o resto que fica se eu subtrair ao fato de que eu ergo o meu braço, o fato de que o meu braço se ergue?" (WITTGENSTEIN, 2015, § 621). A passagem permite perceber a maneira com que Wittgenstein trata os conceitos da vontade e do querer, apresentada no sentido de que uma diferença deve aparecer entre uma ação voluntária e uma ação involuntária, que seria aquele "resto", algo que poderia ser encontrado na própria ação voluntária que a distingue da ação involuntária. Determinar o que seria esse elemento foi um dos grandes temas da filosofia e as teorias com as quais Wittgenstein debate são aquelas que entendem que este elemento deveria ser compreendido como a causa da ação voluntária. Sendo assim, a ação voluntária seria o resultado de algo que acontece com o sujeito, seja um ato mental seja algum tipo de experiência que provoca a ação voluntária e que, como tal, poderia ser encontrado e observado nas próprias ações ou como algo a ser encontrado no sujeito da ação, algo que aconteça ou que se passe com o sujeito. 
Wittgenstein não concorda com estas abordagens e dispensa à ação voluntária um tratamento muito diferente, mostrando que a compreensão do que é uma ação voluntária tem como base a clarificação dos conceitos relativos à vontade, a intenção, ao querer e outros que fazem parte de um jogo de linguagem em que as ações voluntárias têm o seu lugar. Com essa abordagem o autor mostra que, apesar de uma aparente uniformidade, os conceitos relacionados com a ação voluntária ocupam papéis muito diferentes em nossos jogos de linguagem. Esta distinção é fundamental para demonstrar que a vontade não é "uma coisa"1 que deva ser investigada diretamente, como marca distintiva encontrada na própria ação como uma propriedade sua ou como algum tipo de ato mental ou experiência do sujeito da ação, mas sim que a voluntariedade deve ser compreendida como regra gramatical para o funcionamento de determinados jogos de linguagem.

Como consequência, se a vontade não é causa da ação será uma forma de dar sentido às ações ditas voluntárias, no conjunto das ações humanas. A noção de regra gramatical permite compreender que a voluntariedade é uma forma de caracterizar a ação tornando-a significativa. Sendo assim, a ação também não poderá ser descrita de uma perspectiva puramente causal mas demanda uma descrição que depende de uma interpretação do sentido da ação de acordo os aspectos que a envolvem.

Por fim, com esta forma de compreender a voluntariedade das ações temos que considerar o sujeito da ação de uma maneira que o envolve com os outros sujeitos numa trama conceitual e prática, na qual interpretam as ações uns dos outros de uma determinada maneira. Isto está diretamente ligado ao fato de que a vontade não é algo a ser encontrado no sujeito isolado, mas sim no fluxo da vida, que envolve intersubjetivamente a todos os participantes daqueles jogos de linguagem.

A seguir apresentaremos algumas considerações acerca destes três pontos. A opção de tratar do tema desta forma se deve ao fato de que Wittgenstein não dispensou ao tema uma análise detalhada e

1 Podemos usar as mesmas palavras que Wittgenstein investe contra a noção de que a sensação é um objeto interno e privado: “Não, de todo! Ela não é uma coisa, mas também não é um nada! 0 resultado foi que tanto podia servir um nada como uma coisa acerca da qual nada se pode dizer. Repudiamos apenas a gramática que se quer aqui impor a nós" (WITTGENSTEIN, 2015, §304). 
conclusiva. Além disso, também considerou que os conceitos envolvidos na avaliação da voluntariedade das ações são conceitos com "limites borrados", o que nos permite pensar diferentes perspectivas acerca da questão; nesse sentido, o que pretendemos é apenas e tão somente pensar algumas destas perspectivas. As observações que serão o suporte destas considerações fazem parte de Investigações filosóficas, Observações sobre a filosofia da psicologia e Da certeza.

\section{Voluntariedade e regras gramaticais}

Nas passagens em que trata do problema da ação voluntária Wittgenstein tem como alvo as tentativas de explicar a vontade como algo que possa ser encontrado na própria ação, isoladamente, e que seria a marca distintiva que faz com que seja voluntária.

É como se algum tipo de acompanhamento estivesse presente nas ações, cuja presença permitiria decidir se a ação considerada é ou não voluntária. Entretanto, como tais elementos não podem ser encontrados na própria ação, a partir da sua observação, considera-se então que deve ser algo que esteja não na própria ação, mas no sujeito da ação, como experiências subjetivas ou um ato da vontade ${ }^{2}$. A decisão acerca da voluntariedade ou não da ação poderia ser resultado de uma investigação acerca da presença ou não de tais acompanhamentos, o que tem sido feito de forma que, muitas vezes, leva justamente à negação da possibilidade de tais ações, haja vista que as experiências têm demonstrado justamente o contrário. Hacker (2010, p. 158), por exemplo, afirma que:

Se a volição for concebida como uma experiência, algo que acontece conosco, o conceito de agência racional e volitiva fica distorcido, se não abolido. Somos agentes responsáveis por nossas ações voluntárias. Mas, se nossas ações são meros movimentos corpóreos causados por desejos, vontades ou impressões que ocorrem em nós, então parece que o agente, o 'si mesmo querente', cai fora do relato.

2 Para uma apresentação detalhada destas teorias bem como as críticas de Wittgenstein a cada uma delas ver HACKER, 2000. 
Para Wittgenstein, o problema com estas teorias é que entendem a ação voluntária tal como uma peça de um mecanismo, como se a ação voluntária fosse o efeito de algo que se passa com o sujeito e, então, a ação voluntária deveria ser uma consequência de algum outro tipo de ato que se passa no próprio sujeito e que produz a ação voluntária. Sendo assim, seria preciso encontrar a causa desse mecanismo, a causa que produz a ação e sem a qual ela não seria possível. Para Wittgenstein, entretanto, a concepção causal da ação voluntária separa ação e vontade, como se pudessem ser explicadas cada uma em si mesmas, o que seria fazer de uma relação interna uma relação externa.

Na passagem do início do texto fica claro que Wittgenstein aceita de imediato a possibilidade da ação voluntária, expressa em termos de uma distinção entre "ergo o meu braço" (voluntária) e "o meu braço ergue-se" (involuntária): não há nenhuma dúvida de que nossas ações podem ser voluntárias, o que está registrado em diferentes passagens, como por exemplo:

Uma criança bate os pés de raiva: isso não é voluntário? E eu sei seja lá o que for de suas sensações de movimento quando ela faz isso? Sapatear de raiva é voluntário. Vir quando se é chamado é, nos arredores habituais, voluntário. Andar, sair para uma volta, comer, falar e cantar involuntariamente seriam andar, comer, falar, etc. em arredores anormais. Por exemplo, quando não se está consciente: quando de resto a pessoa age como se estivesse sob narcose; ou quando o movimento acontece, e passa-se a não se saber nada sobre ele tão logo se feche os olhos; ou quando não se pode ajustar o movimento por mais que se tente fazê-lo, etc. (WITTGENSTEIN, 2008, I, § 902, grifos do autor).

Depreende-se dessas passagens que, para Wittgenstein, a diferença se dá em termos daquilo de que somos pacientes, algo que acontece conosco e que não podemos evitar ou fazer diferente e aquilo de que somos agentes, aquilo que depende de nossa vontade para acontecer e que poderia ter sido feito de outra maneira: uma diferença entre acontecer e fazer. Para Wittgenstein, entretanto, essa diferença tem de ser considerada enquanto uma diferença conceitual do jogo de linguagem dos termos ligados à vontade e não como algo a ser encontrado no sujeito como causa da ação. 
De acordo com uma análise gramatical da ação voluntária é preciso lembrar que, a partir do argumento da linguagem privada, Wittgenstein não admite que nossos conceitos possam ter seu significado determinado por qualquer evento, objeto ou processo supostamente interior e privado. Neste sentido é que também se tem de considerar os conceitos relativos a ação voluntária. A própria compreensão da questão acerca da vontade e da voluntariedade deve ser considerada de um ponto de vista que leve em consideração o uso dos termos relacionados às ações voluntárias, e, também, dos contextos efetivos em que se realizam, ou seja, tem de levar em conta a práxis efetiva dos sujeitos em sua vida cotidiana ou, como diria Wittgenstein, no fluxo da vida, considerado como um espaço público de interação. Não se pode isolar um termo qualquer e retirá-lo dessa trama conceitual-prática que o envolve. Assim, perguntar diretamente sobre o que é a "vontade", se a "vontade é livre" e coisas do tipo, abole o vínculo dos conceitos com as práticas comuns em que avaliamos nossas ações particulares de uma perspectiva de acordo com a qual podem ou não ser voluntárias.

Além disso, não podemos perder de vista que as investigações filosóficas acerca da vontade devem estar de acordo com a observação de que: "nossa investigação não se dirige para os fenômenos, mas, poder-se-ia dizer, para as possibilidades dos fenômenos. Isto significa que o que trazemos à consciência são os gêneros de proposições que fazemos acerca dos fenômenos" (WITTGENSTEIN, 2015, § 90) e ainda: "um paralelo enganador: a Psicologia trata dos processos da esfera do psíquico, como a Física trata dos processos da esfera do físico. Ver, ouvir, pensar, sentir, querer, não são no mesmo sentido objetos da Psicologia como o movimento dos corpos e os fenômenos elétricos são os objetos da Física" (WITTGENSTEIN, 2015, § 571).

De acordo com a análise gramatical do conceito de ação voluntária, Wittgenstein demonstra que ação e vontade estão numa relação interna, o que significa que o significado de ação e o significado de vontade não podem ser compreendidos separadamente, a gramática destes conceitos não permite fazer essa separação. Disto se segue que as ações voluntárias não são causadas pela vontade, mas que as próprias ações, em si mesmas, são ou não voluntárias, ou, dito de outro modo, 
a vontade se mostra na própria ação realizada. Quando julgamos uma ação como sendo ou não voluntária o que julgamos é a própria ação e não se algo acompanha ou não a ação em questão. Isso é assim porque, para Wittgenstein, certas ações são em si mesmas voluntárias, são casos paradigmáticos de ações voluntárias; estas ações são intrinsecamente voluntárias, de modo que dizer delas que são involuntárias seria totalmente sem sentido. E estas são ações comuns e cotidianas tais como "falar, escrever, andar, levantar algo, representar-se algo. Mas também: pretender, tentar, esforçar-se, por falar, escrever, levantar algo, representar-se algo, etc. (WITTGENSTEIN, 2015, § 615).

Aprendemos a julgar se as ações são ou não voluntárias de acordo com um modo de agir mais fundamental em que a pergunta sobre sua própria voluntariedade ainda não é colocada e problematizada. Esse modo de agir vai se tornando mais complexo e passa a ser articulado linguisticamente. Isto significa que em nossa vida cotidiana não surgem dúvidas acerca da voluntariedade de certas ações, não observamos uma pessoa escrevendo e ficamos em dúvida se ela escreve voluntária ou involuntariamente e, por isso, faria menos sentido ainda tentar encontrar uma prova ou algo que possa justificar nossa consideração de que a ação é sim voluntária: "como sei se a criança come, bebe, anda etc. de forma voluntária ou não voluntária? Eu pergunto o que ela sente? Não; comer, assim como todos comem, é voluntário" (WITTGENSTEIN, 2008, I, § 763).

Para esclarecer esse ponto é preciso ter em mente que em sua filosofia tardia Wittgenstein entende que o funcionamento da linguagem envolve de maneira irredutível as diferentes funções, os diferentes papéis ou ainda os diferentes lugares que as palavras e as sentenças ocupam na linguagem. E no Da certeza, ao analisar as tentativas de Moore de provar a certeza de certos truísmos do senso comum, ou ainda de provar a existência do mundo externo com base em algumas premissas que considerou evidentes e absolutamente certas, Wittgenstein demonstra que o maior equívoco de Moore foi não ter percebido a 
diferença de categorias entre certas proposições de nossa linguagem (WITTGENSTEIN, 2000, § 308) $)^{3}$.

As proposições que Wittgenstein está ali considerando são aquelas que chamou de proposições gramaticais, as quais têm a forma de proposições empíricas, mas que, no entanto, ocupam um lugar muito diferente destas últimas e têm funções muito distintas no todo de um jogo de linguagem. Se as proposições empíricas podem ser consideradas lances dentro de um jogo de linguagem, as proposições gramaticais muitas vezes ocupam o lugar de regras gramaticais e como tal elas determinam o funcionamento dos jogos de linguagem. As proposições gramaticais são os fundamentos dos jogos de linguagem e não podem ser tomadas como lances dentro dele. O exemplo de Wittgenstein, "existem objetos físicos", nos permite perceber claramente esta distinção. No parágrafo 36 de Da Certeza escreve:

'A é um objeto físico' é uma indicação que damos a alguém que não percebe ainda o que significa 'A' ou o que significa 'objeto físico'. Assim, é uma indicação sobre o uso de palavras, e 'objeto físico' é um conceito lógico (tal como cor, quantidade...). E é por isso que não pode ser formulada uma proposição como 'Há objetos físicos' (WITTGENSTEIN, 2000, § 36).

O erro de Moore foi ter tentado provar a verdade de uma proposição tal como esta: "existem objetos físicos". Entretanto, esta não é uma proposição empírica que possa ser provada verdadeira ou falsa, mas sim uma regra gramatical para que possamos falar dos objetos a nossa volta e como tal é um pressuposto nunca questionado destes jogos de linguagem: "as crianças não aprendem que existem livros, que existem poltronas, aprendem a ir buscar livros, a sentarem-se em poltronas, etc." (WITTGENSTEIN, 2000, § 476). São modos de agir que estão na origem de nossa linguagem, o que significa que quando aprendem a linguagem as crianças aprendem um determinado modo de agir no mundo, um determinado comportamento.

\footnotetext{
3 '"Saber' e 'certeza' pertencem a diferentes categorias... Estou inclinado a crer que nem tudo que tem a forma de uma proposição empírica 0 é".
} 
A "voluntariedade das ações" segue o mesmo caminho que "objetos físicos" no sentido em que ocupam os mesmos lugares na linguagem ou exercem os mesmos papéis nos jogos de linguagem. As crianças aprendem a comer, beber e andar, não aprendem a comer, beber e andar voluntariamente.

Com o tempo vão aprendendo formas de agir mais complexas, aprendem a julgar as ações dos outros e a justificar suas próprias ações, por exemplo. Mas os lances adequados que podem ser realizados nos jogos de linguagem são relativos à avaliação de ações particulares diante de sua voluntariedade ou não. O aprendizado de conceitos tais como vontade, intenção, querer, implica em aprender a comportar-se de determinadas maneiras, tais como responsabilizar alguém, pedir e apresentar justificativas, comprometer-se, julgar, condenar, absolver, repreender e tantas outras.

O que não pode ser um lance efetivo dentro de um jogo de linguagem é questionar a própria possibilidade da ação voluntária, pois esta possibilidade está garantida por regras gramaticais que fundamentam e, assim, possibilitam aquele jogo de linguagem. As regras gramaticais que envolvem a vontade têm como paradigma determinadas ações, das quais não faz nenhum sentido questionar acerca de sua voluntariedade ou não. Ações comuns e cotidianas tais como andar, comer, beber, jogar uma partida de xadrez são consideradas ações intrinsecamente voluntárias, na exclusiva medida em que, quanto às nossas práticas cotidianas, não faz nenhum sentido questionar se são ou não voluntárias.

A questão acerca da possibilidade ou não da ação voluntária perde o sentido, na medida que não é uma questão empírica, que possa ser respondida com um sim ou não. A voluntariedade das ações é uma regra gramatical, é uma proposição fulcral cuja problematização colocaria em xeque todo o jogo de linguagem. Não se pode tratar diretamente do "voluntário", perguntar diretamente sobre a existência ou não da vontade. O que fazemos é julgar cada ação particular sobre sua voluntariedade, não tendo como pano de fundo ou fundamento desta pergunta as regras gramaticais que definem nosso conceito de voluntário.

Considerar a voluntariedade como regra gramatical implica em considerá-la como fundamento de uma série de práticas cotidianas, que seriam impossibilitadas se assim não fosse. Da mesma maneira que não nos é ensinado explicitamente que "objetos físicos existem", mas que 
aprendemos isso de forma implícita na medida em que aprendemos a lidar com mesas, cadeiras, livros, etc. Além disso, também não nos é ensinado explicitamente que ações voluntárias existem ou que a vontade existe, mas aprendemos um conjunto de ações que são paradigmaticamente voluntárias e, a partir dela, vamos desenvolvendo mais e mais o jogo de linguagem dos motivos e razões, o jogo de linguagem onde se encaixam as ações voluntárias. E podemos então afirmar que esse "modo comum de agir" é o fundamento último das nossas ações voluntárias, um modo de agir que se cristaliza em regras gramaticais.

\section{A caracterização da ação}

Um dos equívocos que levam à concepção causal da vontade está relacionado com a noção de que querer é uma ação, tal como andar, comer, escrever, etc. Esta ação deveria acontecer enquanto um ato da vontade, ato este que tornaria então as outras ações voluntárias ou não. $\mathrm{O}$ ato da vontade seria anterior a qualquer outra ação e explica a voluntariedade, em termos, de um ato do sujeito que age voluntariamente ou não. Este equívoco é gerado pelo fato de que quando somos questionados sobre por que agimos de uma determinada maneira podemos responder "porque quis", "porque quero", "porque queria" dando a impressão que este "quis", "quero" ou "queria" são ações. O problema, segundo Wittgenstein, é que então o próprio querer deveria poder ser voluntário ou não, mas isso não faria o menor sentido:

no sentido no qual eu sou de todo capaz de produzir qualquer coisa (como dores de estômago, comendo excessivamente), assim também sou capaz de produzir um ato de querer. Neste sentido eu produzo o ato de querer ir nadar ao saltar para a água. Eu queria, de fato, dizer o seguinte: não me é possível não querer o querer; isto é, não tem qualquer sentido falar em querer-querer. 'Querer não é o nome de uma ação; logo, também não é o nome de uma ação voluntária (WITTGENSTEIN, 2015, § 613).

Ou seja, querer não é uma ação e também não é a causa de uma ação. O querer está ligado com a justificação da ação, justificação esta 
que remete direta e imediatamente ao sujeito da ação. E se esta justificação não se dá em termos de causa da ação, se dá, sim, em termos de motivos e razões que o sujeito tem para agir da forma como agiu e para justificar ter agido desta forma.

Em uma passagem de Observações sobre a filosofia da psicologia, Wittgenstein (2008, I, § 850) afirma que: "tiram-se dos movimentos involuntários conclusões bem diferentes das que se tiram dos voluntários: isto caracteriza o movimento voluntário"). Ora, a maneira de "caracterizar" as ações como ações voluntárias é justamente a ligação desta com "porque quis", "porque quero", "porque queria", que remetem ao conceito de vontade, mas agora compreendida como "uma capacidade de quereres, metas e propósitos arrazoados, de deliberação e ação por razões" (HACKER, 2010, p. 152).

A vontade assim compreendida revela novamente sua relação intrínseca com um modo de agir no mundo, com maneiras de comportar-se, o que demanda o desenvolvimento de capacidades específicas. Para tanto, surge a necessidade de um pano de fundo regrado, no qual estão fundamentados os conceitos de voluntariedade e vontade, enquanto regras gramaticais, bem como as circunstâncias dentro da qual esta ação foi realizada. A partir de todo este contexto é que se pode caracterizar uma ação como ação voluntária, de acordo com os motivos e razões que são apresentadas para realizar a ação da maneira como foi realizada: "se me perguntam: 'Você vai agir assim?' - eu reflito sobre razões para e razões contra" (WITTGENSTEIN, 2008, I, § 815).

Além disso, conforme define HACKER (2010, p. 153) "movimentos humanos característicos são ações das quais faz sentido dizer que são voluntárias, intencionais, feitas ou realizadas deliberadamente ou de propósito, por uma razão ou com algum motivo". Ou seja, propósitos, razões e motivos dão o sentido da ação e isto significa que um mesmo movimento pode ter diferentes sentidos na medida em que é realizado com diferentes propósitos, razões ou motivos.

Poderíamos agora perguntar se essa palavra de fato se referiria simplesmente ao comportamento, simplesmente às alterações corporais. E é isto o que queremos negar. Simplificar o uso da palavra dessa maneira não nos 
leva a nada. Ela se refere ao comportamento em meio a certas circunstâncias exteriores. Quando observamos essas circunstâncias e aquele comportamento dizemos que alguém está [...] (WITTGENSTEIN, 2008, II, §166).

Por isso mesmo uma explicação de tipo causal é no mínimo insuficiente para esgotar o sentido da ação humana, uma vez que tenta explicar o movimento de uma maneira unificada, encontrando a sua causa comum. Entretanto, para compreender o sentido da ação torna-se necessária uma outra forma de descrição, pois um mesmo movimento pode resultar em diferentes ações e há até mesmo casos em que uma ação é realizada na ausência de qualquer movimento. Em relação aos movimentos corporais, uma ação pode ser considerada tais movimentos dentro de uma determinada perspectiva. Ou seja, a ação vai além do movimento pura e simplesmente considerado na medida em que ela é caracterizada como ação. Neste sentido, podemos dizer que o movimento pode ser visto como ação na medida em que estes movimentos sejam dados dentro de certas circunstâncias. Estas circunstâncias são os arredores da ação: "voluntários são certos movimentos com seus arredores normais de intenção, aprendizado, tentativas, ações. Movimentos dos quais faz sentido dizer que às vezes são voluntários, às vezes involuntários, são movimentos num arredor especial" (WITTGENSTEIN, 2008, I, § 776).

Longe de ser um acompanhamento interno de movimentos exteriores, o querer e a vontade se revelam no próprio comportamento do sujeito, como o desenvolvimento de uma capacidade de agir de uma determinada maneira, de acordo com o sistema de regras que coordena tais movimentos e que aparece como razão ou motivo para a ação:

Como alguém aprende a chamar um cubo de açúcar de "açúcar"? Como ele aprende a atender ao pedido "Dê-me um cubo de açúcar"? Como ele aprende as palavras "Um cubo de açúcar, por favor" - ou seja, a expressão de um desejo?! Como aprende a entender a ordem “Jogue!"? E a expressão de intenção "Eu vou jogar agora"? Está bem os adultos podem demostrar à criança, proferindo a palavra e jogando logo em seguida - mas agora a criança tem de imitar isso. ("Mas isso só é a expressão da intenção se a criança tem a intenção efetivamente em seu espírito." - Porém, quando será que dizemos que esse é o caso?) 
E como ela aprende a usar a expressão "Naquela hora, eu estava prestes a jogar"? E como sabemos que naquela hora ela realmente estava naquele estado de espírito que $e u$ chamo de "estar prestes a..."? Depois que lhe foram ensinados tais e tais jogos de linguagem, ela usa, em tais e tais ocasiões, as palavras que os adultos proferiram nesses mesmos casos ou usa forma de expressão mais primitiva que encerra relações essenciais com o que foi aprendido anteriormente, e os adultos substituem essa forma mais primitiva pela forma de expressão regular" (WITTGENSTEIN, 2008, I, § 163).

Realizamos nossas ações cotidianas sempre dentro de certos padrões de algum jogo de linguagem; desde que nascemos estamos já dentro de jogos de linguagem. E os jogos de linguagem são constituídos por regras gramaticais, regras estas que determinam o significado das palavras que dele fazem parte, mas também das ações que a ele estão associadas, uma vez que um jogo de linguagem é um todo de palavras e atividades a ele associados. As ações são sempre descritas da perspectiva de um jogo de linguagem e é preciso, por isso, levar em consideração as regras que determinam o significado das palavras com as quais descrevemos a ação naquela perspectiva; não há uma única perspectiva de descrição da ação.

A passagem sobre a caracterização da ação permite ver como o movimento é enredado numa rede conceitual que o torna ação. De maneira análoga, isto também acontece com determinados exemplos do ver aspectos. Eu não posso encontrar o aspecto diretamente numa figura, ele não é algo que possa ser descrito de forma direta, mas precisa ser compreendido de acordo com um pano de fundo que organiza a figura de uma determinada maneira. Nós podemos ver o aspecto porque aprendemos a interpretar a figura de uma determinada perspectiva e podemos a partir disso descrever a figura desta perspectiva. Mas a figura como tal será sempre a mesma, o que se revelam são aspectos que nós aprendemos a ver de acordo com as circunstâncias em que a figura nos é dada.

Da mesma maneira:

Avaliamos uma ação contra seu pano de fundo na vida humana, e este pano de fundo não é monocromático, mas poderíamos imaginá-lo como um padrão filigranado muito complicado, o qual 
certamente não poderíamos copiar, mas poderíamos voltar a reconhecer pela sua impressão geral.

O pano de fundo é o bulício da vida. E nosso conceito designa algo nesse bulício (WITTGENSTEIN, 2008, II, § 624 e § 625, grifo do autor).

No "bulício da vida" os homens desenvolvem seus costumes, seus hábitos, suas instituições, que estão relacionados diretamente às suas ações. É neste espaço que podemos encontrar a possibilidade de fazer algo "porque se quer", o que vai variar de acordo com as variações nas próprias formas de vida em que estão enraizados aqueles costumes, hábitos, instituições. Exatamente por isso, o sentido das ações não pode ser reduzido a uma explicação unitária, pois este sentido modifica de acordo com as modificações que acontecem em nossas formas de vida.

Não é apenas a própria ação em si mesma e isolada que pode ser dita voluntária ou não, mas ação nesse contexto. Se assim não procedemos, ficamos como que enfeitiçados, buscando aquele "resto" que deveria se apresentar na ação como causa da sua voluntariedade. Entretanto, o que se precisa encontrar para compreender a ação humana voluntária não é a sua suposta causa, mas sim o seu significado. Neste sentido, os movimentos não são significativos, por isso podem ser descritos de uma forma unitária: o ato de levantar o braço terá sempre as mesmas causas, mas o seu significado será diferente na medida em que se levanta o braço para pegar algo, para cumprimentar alguém, etc. Além disso, o significado das ações, estando ligados às razões, ligam-se também aos valores que damos às ações. Das razões, mas não das causas é que dizemos ser boas ou más, aceitáveis ou não. São as razões que permitem a avaliação de uma ação, o que nunca aconteceria de um ponto de vista puramente causal.

\section{O sujeito e a perspectiva de primeira pessoa}

E se as ações podem ser caracterizadas como ações voluntárias elas também podem ser descritas desta perspectiva, e não apenas de uma perspectiva causal. Temos então, pelo menos, duas formas distintas de descrição da ação, uma em que se tomam as causas para a ação 
e outra em que se tomam os motivos e razões. O equívoco é a ânsia de generalização que faz pensar todos os nossos conceitos de uma única perspectiva, que leva a acreditar que a voluntariedade pode ser descrita por meio de proposições empíricas, no sentido de que deveriam referir um determinado "objeto" qualquer, cuja presença tornaria o ato voluntário. Entretanto, estas proposições, na medida em que apresentam os motivos e razões do próprio sujeito da ação podem ser questionadas acerca de sua correção ou não, se são ou não adequadas, justas, boas ou más, o que demanda outro tipo de justificação.

Da mesma maneira que ver os aspectos de uma figura demanda uma atitude compreensiva para algo que não pode ser encontrado como propriedade da figura (tal como a cor ou a forma), ver a ação como ação voluntária demanda essa atitude compreensiva para com os motivos e razões da ação. Motivos e razões não podem ser reduzidos a algum esquema causal, nem a algum tipo de propriedade da ação, mas sim como um modo de se dar daquela ação.

Quando fazemos essa distinção e entendemos que a ação voluntária deve ser compreendida de acordo com esse pano de fundo gramatical que caracteriza a ação, podemos também compreender a diferença entre movimentos e comportamentos daquilo que é propriamente a ação. Peter Hacker (2001, p. 64) mostra que há uma diferença fundamental entre movimentos ou comportamentos e ação propriamente: "um movimento constitui uma ação se o agente pudesse ter feito de outra forma" e "o comportamento é julgado um ato apenas se é de uma espécie tal que possa ser feito intencionalmente. No caso de agentes racionais, geralmente é o comportamento de uma espécie que pode ser feito por razões, pode ser decidido acerca. O horizonte da ação de agentes racionais coincide com o domínio de sua vontade" (HACKER, 2010, p. 148). Esta forma de entender a ação humana a liga necessariamente à voluntariedade, que seria a marca distintiva de uma ação em relação aos movimentos e comportamentos. Das ações, mas não dos movimentos, podemos perguntar pelo "por que", que remete imediatamente ao sujeito da ação e isso implica que "o comportamento era de uma espécie que tipicamente está sob controle do agente e pelo qual ele pode ser tido como responsável, que é algo tal que um agente 
normalmente pode fazer ou evita fazer à vontade, e pode ter uma razão para fazer" (HACKER, 2010, p. 166).

O comportamento humano pode ser descrito, portanto, de duas perspectivas, enquanto movimento e enquanto ação. Quando se trata de movimento, podemos fazer a descrição do que acontece de um ponto de vista de terceira pessoa, observando "de fora" o que se passa e demonstrando as causas do movimento, como por exemplo, o que é que faz com que o braço se levante, ou seja, a descrição de algo que acontece com o sujeito. Podemos descrever os movimentos de uma perspectiva de terceira pessoa puramente, buscando as causas que o explicam, mas quando é de ação que se trata, temos que envolver a perspectiva da primeira pessoa, que está ausente da explicação causal. A perspectiva de primeira pessoa envolve o sujeito de uma forma incontornável, na medida em que a ação é dele e não aconteceria de outra maneira que não pelas razões que ele próprio tem a oferecer. Há um vínculo entre a ação e o sujeito e este é tão forte que um não pode ser compreendido sem o outro.

Se o querer fosse algum tipo de experiência no sujeito, então poderia ser perfeitamente concebível o fato do próprio sujeito acompanhar sua ação de uma perspectiva exterior e descrever o que se passa com ele mesmo quando age voluntariamente. Essa experiência deveria ser objeto de observação pelo próprio sujeito agente. Mas não é o que acontece, pois, quando o sujeito apresenta os motivos de sua ação, não faz isso no sentido de observar o que se passa em si mesmo ou faz uma descrição dessa experiência, mas recorre a um pano de fundo regrado, constituído pela linguagem, este que é o lugar em que se constituem os motivos e razões. A descrição da ação nestes termos depende mais de uma interpretação da mesma do que uma explicação (do tipo das explicações causais), na medida em que as razões estão imersas neste fundo comum das nossas formas de vida, este "contexto histórico onde os seres humanos se encontram" (HACKER, 2001, p. 68).

As razões e os motivos se constituem intersubjetivamente e se cristalizam na linguagem. Cada sujeito particular recorre a esse pano de fundo para justificar sua ação, é aí que encontra aquilo que pode ou não contar como razão para sua ação. É nesse sentido que Wittgenstein afirma que: 
Existe um determinado jogo conjunto de movimentos, palavras, caras, como as manifestações de relutância ou prontidão que caracterizam os movimentos voluntários do homem normal. Quando chamamos a criança, ela não vem automaticamente: há ali, por exemplo, o gesto "Não quero!". Ou há a vinda alegre, a decisão de vir, a fuga com sinais de medo, os efeitos da persuasão, todas as reações do jogo, os sinais de reflexão e seus efeitos (WITTGENSTEIN, 2008, I, § 841).

Só se pode querer fazer algo na medida em que haja um pano de fundo regrado que mostre o que é a vontade, a intenção, o querer. Entretanto, esse pano de fundo regrado que explica a voluntariedade só pode existir em um espaço público compartilhado, uma forma de vida que implica na existência do sujeito entre outros sujeitos, pois: "se apenas uma pessoa, uma só vez, tivesse feito um movimento corporal - poderia haver a questão sobre se ele foi voluntário ou involuntário?" (WITTGENSTEIN, 2008, I, § 897). Portanto, trata-se de um sujeito que tem de ser compreendido intersubjetivamente, pois em relação à ação voluntária, obviamente esta ação depende de poder dizer que ela é ação de um sujeito, como tudo o que isso implica, mas também que envolve os outros sujeitos numa trama conceitual e prática, na qual os sujeitos interpretam as ações uns dos outros como voluntárias ou não.

O sentido da realização de uma ação voluntária envolve os sujeitos de tal maneira que cria compromissos no mundo, do sujeito de quem se diz agir voluntariamente com os outros sujeitos que estão envolvidos na prática. Vê-se assim que esta ação não pode ser algo que se esgota no próprio sujeito. Se para podermos afirmar que uma ação é ou não voluntária tivéssemos que investigar algo que se passa no sujeito, então muito daquilo que costumamos associar com a ação voluntária deixaria de ter sentido. Este é o sentido último da voluntariedade: ela está imbricada com as ações humanas no mundo, ações que por sua vez implicam necessariamente linguagem e sociabilidade. 


\section{Considerações finais}

A busca pelo significado dos conceitos leva a uma compreensão do significado da própria ação, na medida em que, como vimos, ação e linguagem são inseparáveis no que diz respeito ao jogo de linguagem da vontade. Wittgenstein oferece uma perspectiva não reducionista para a compreensão da questão, o que não significa que as investigações científicas não tenham valor ou importância nesse assunto, mas sim perceber que a ação humana no mundo não tem sua significação esgotada em explicações científicas.

A ação voluntária não se esgota em um mecanismo causal que produz um determinado movimento, na medida em que um mesmo movimento pode revelar diversas e diferentes significações de acordo com as razões oferecidas pelo sujeito da ação. Estas razões devem ser buscadas no fundo comum de nossas formas de vida, no entrelaçamento entre linguagem, cultura e história, recusando as explicações causais como apropriadas para "resolver" questões desse tipo.

Se as explicações causais são importantes para explicações científicas, por outro lado não substituem um olhar atento e uma consideração de aspectos tais como nossos interesses e objetivos, a afetividade, as vivências, aspectos que estão profundamente ligados com a ação humana no mundo. Desta maneira, uma compreensão da ação nesta perspectiva poderá revelar aspectos muito mais abrangentes da própria ação.

Na complexidade de nossos jogos de linguagem e de nossa forma de vida temos o pano de fundo que dá significado às nossas ações, pano de fundo este que é moldado de acordo com as circunstâncias familiares das estruturas sociais e institucionais, construídas ao longo de nossa história natural. Assim, podemos afirmar que não há ações voluntárias senão para os sujeitos e para as sociedades das quais fazem parte, que são aqueles capazes de compreender uma ação como ação voluntária, pois elas estão inscritas nas práticas comuns e são reconhecidas como tal por todos aqueles que juntos tomam parte desta prática. Em Wittgenstein temos, portanto, o reconhecimento da irredutibilidade de um espaço público de convivência para que possamos julgar as ações como ações voluntárias, e o ponto fundamental é justamente os juízos que fazemos 
com todas as implicações práticas que deles decorrem, tal como responsabilização, imputação moral, condenação entre outros.

O significado das ações humanas não pode ser compreendido separando-se as ações deste pano de fundo. Este significado vai tornando-se mais e mais sofisticado, de acordo com a cada vez maior complexidade das nossas formas de vida. O que acontece, porém, é que sua raiz última são os modos de agir mais fundamentais, aquelas reações primitivas que se dão enquanto "fatos naturais extremamente gerais". É esse modo comum de agir que vai se tornando linguisticamente articulado, que é a base última de compreensão das ações e, portanto, dos conceitos a elas relacionados.

\section{Referências}

HACKER, P. M. S. Wittgenstein: mind and will. Oxford: Blackwell, 2000.

HACKER, P. M. S. Wittgenstein: connections and controversies. Oxford: Oxford University Press, 2001.

HACKER, P. M. S. Natureza humana: categorias fundamentais. Porto Alegre: Artmed, 2010.

WITTGENSTEIN, L. Da certeza. Lisboa: Edições 70, 2000.

WITTGENSTEIN, L. Observações sobre a filosofia da psicologia. Trad. de Ricardo H. P. Machado. Aparecida: Idéia e Letras, 2008. v. I; II.

WITTGENSTEIN, L. Tratado lógico-filosófico e Investigações filosóficas. 6. ed. Trad. M. S. Lourenço. Lisboa: Fundação Calouste Gulbenkian, 2015.

Recibido: $16 / 02 / 2018$

Received: 02/16/2018

Aprobado: 28/05/2018

Approved: 05/28/2018 